\title{
Diets, Diseases, and Discourse: Lessons from COVID-19 for Trade in Wildlife, Public Health, and Food Systems Reform
}

\author{
Angela Lee ${ }^{1}$ (D) Adam R. Houston ${ }^{2}$ \\ Accepted: 20 July 2020 / Published online: 28 July 2020 \\ (C) Springer Nature Switzerland AG 2020
}

\begin{abstract}
The COVID-19 pandemic has brought to light significant failures and fragilities in our food, health, and market systems. Concomitantly, it has emphasized the urgent need for a critical re-evaluation of many of the policies and practices that have created the conditions in which viral pathogens can spread. However, there are many factors that are complicating this process; among others, the uncertain, rapidly evolving, and often poorly reported science surrounding the virus' origins has contributed to a politically charged and often rancorous public debate, which is concerning insofar as the proliferation of divisive discourse may hinder efforts to address complex and collective concerns in a mutually cooperative manner. In developing ethical and effective responses to the disproportionate risks associated with certain food production and consumption practices, we argue that the focus should be on mitigating such risks wherever they arise, instead of seeking to ascribe blame to specific countries or cultures. To this end, this article is an effort to inject some nuance into contemporary conversations about COVID-19 and its broader implications, particularly when it comes to trade in wildlife, public health, and food systems reform. If COVID-19 is to represent a turning point towards building a more equitable, sustainable, and resilient world for both humans and nonhuman animals alike, the kind of fractioning that is currently being exacerbated by the use of loaded terms such as "wet market" must be eschewed in favour of a greater recognition of our fundamental interconnectedness.
\end{abstract}

Keywords COVID-19 · Pandemic $\cdot$ Zoonotic disease $\cdot$ Discourse $\cdot$ Wet market - Wildlife trade Food systems $\cdot$ Public health

Angela Lee

angela.lee@uottawa.ca

1 Faculty of Law, Ryerson University, Toronto, ON, Canada

2 Faculty of Law, University of Ottawa, Ottawa, ON, Canada 


\section{Introduction}

The COVID-19 pandemic has exposed myriad weaknesses and outright failings in our food, health, and market systems. At the same time, this reckoning has generated momentum in favour of forceful demands for change. Unfortunately, among the uglier consequences of the pandemic - quite apart from the devastating degree of death and suffering it has brought about — has been the divisive discourse that it has spawned, and the attendant discriminatory behaviour that it has stoked. Perhaps most notably, there has been a visible spike in antiChinese and broader anti-Asian sentiment in many parts of the world as a result of the widespread hypothesis that the virus' epicentre was the Huanan Seafood Wholesale Market in Wuhan, China. ${ }^{1}$ Despite the protestations of experts, the continuing use of labels like "China flu", "Wuhan virus" or "kung flu", especially by high-profile actors like Donald Trump (Nakamura 2020; Zimmer 2020), further fuels the misguided belief that blame for the pandemic falls squarely on the shoulders of one country or group of people.

Presently, there remains a lack of scientific consensus as to how exactly the virus first emerged in humans, but many signs indicate that conditions at the impugned market in Wuhan, such as the offering of wild animals for sale, played a noteworthy role in its spread. This market is not necessarily an exceptional case; instead, it is a particularly extreme example of an outbreak of disease in humans resulting from the circumstances under which nonhuman animals are traded and consumed. There are multiple elements of the way nonhuman animals are currently being used in our food systems - including, but not limited to, public health concerns underscored by COVID-19- that are troubling. No set of cultural practices related to the production and consumption of animal products has a monopoly on the risks and issues that are raised.

For instance, the agricultural use of antibiotics in healthy animals to spur their growth, which is a common practice in many countries, poses a serious threat to human health by promoting antibiotic resistance in bacteria that can also affect human health (World Health Organization 2017), making infections like Salmonella and E. coli harder to treat. Similarly, enclosing a variety of animals in small, confined areas and keeping them in unsanitary conditions, as seen in most forms of intensive factory farming, facilitates the transmission of viral pathogens both among and between species (Graham et al. 2008). The evidence strongly suggests that change is needed if we are to make serious efforts to prevent future pandemics. Though this much is obvious, the question of what kind of change is necessary, and on the part of whom, is considerably more complicated. This is not only a political, social, or a scientific question, but also an ethical one.

There are many ways in which food practices are culturally specific, both on the production and consumption ends. Accordingly, at least some degree of cross-cultural sensitivity is warranted in dialogues regarding food systems reform, whether at the national or at the international level. To be clear, the fact that certain practices are more closely associated with a specific culture certainly does not mean that those situated outside of that culture cannot legitimately comment on such practices without being vulnerable to charges of ethnocentrism or cultural imperialism. Even the most traditional of cultural practices are not rendered, by virtue of their long histories alone, immune from critique or exempt from calls to adapt to new

\footnotetext{
${ }^{1}$ We acknowledge that pandemic-related racism has also manifested in other ways, including in anti-African sentiment in China (Vincent 2020; Burke et al. 2020), as well as the fact that instances of other kinds of discrimination, like homophobia (Sternlicht 2020), have also increased in some parts of the world.
} 
conditions (Robinson 2013). Particularly where such practices have already undergone large shifts in their scale and the manners in which they are carried out, advocating for a critical reevaluation of how production and consumption can be modified to mitigate public health risks is not only appropriate, but also imperative, as COVID-19 has aptly illustrated.

That being said, the charges levied against certain cultural practices too often descend into sweeping condemnations of an entire culture itself. In this way, they can readily be co-opted by racist and/or xenophobic agendas as further justification for pre-existing biases. This is especially the case when the terms by which such practices are discussed - such as "wet market", in this particular instance — become culturally loaded. Moreover, to present the wholesale abolition of retail settings like wet markets and/or the elimination of the consumption of all or certain types of animal products as apposite solutions to the concerns that they raise is highly oversimplistic, and serves to sideline a number of other important dimensions of the underlying problems.

This article is an effort to inject some nuance into contemporary conversations about COVID-19 and its broader implications for animal production and consumption, public health, the environment, and various forms of justice. As legal scholars with expertise in food, environmental, animal, health, and equity-related issues, we contend that regardless of the origins of novel pathogens in food systems, ethically appropriate responses to the risks and harms that they engender must holistically account for the full context in which they are situated. To this end, perspectives from the social sciences have valuable contributions to make in identifying underlying drivers of "disease emergence, transmission, and spread that are linked to human behaviours, and the sociocultural and political systems that guide and constrain them" (1885: Janes et al. 2012).

We begin this article by outlining some of the main problems associated with producing and consuming animal products that are salient to the spread of infectious disease in contemporary circumstances. This article then goes on to discuss how discourse can skew the direction of a conversation, imbuing a term such as "wet market" with cultural and political baggage that overshadows specific risks and effective measures to ameliorate them. The adoption of extreme, oversimplistic, and reactionary solutions does not only create unfair and uneven impacts, but worse still, over the long run, may not even deliver the results that were envisioned. Consequently, we argue that cultivating a careful attention to context can help produce both more ethical and more effective outcomes. Finally, the conclusion stresses the importance of focusing on mitigating shared risks wherever they arise, rather than placing responsibility for collective concerns with global ramifications only on certain parties.

\section{Diets, Disease, and Drivers of Change}

Many disease outbreaks in humans have been traced back to close interactions between humans and nonhuman animals. Zoonotic diseases are caused by pathogens that are transmitted between animals and humans. Animal to human disease transmission is not a new phenomenon; familiar diseases like measles, tuberculosis, and more recently, human immunodeficiency virus (HIV) all have their historical origins as animal diseases that ultimately adapted to human hosts. The cause for concern is that numerous novel zoonoses have been identified in recent years. Some of these only cause sickness on a minor scale, while others, like severe acute respiratory syndrome (SARS), have been responsible for hundreds of deaths.

As is now made patently clear by the unprecedented impacts of the COVID-19 outbreak, zoonotic diseases are a pressing challenge in terms of global health, and are likely to become 
more significant in the future, especially if the escalation of human activities like trade and travel that facilitate the rapid international spread of such diseases resumes as before. Poorly regulated and/or illegal trade in wildlife, irrespective of the purpose, creates disproportionate risks insofar as it provides fertile breeding grounds for the emergence, amplification, and diffusion of zoonotic diseases. However, risks for both humans and nonhuman animals exist in virtually any setting that involves confining large numbers of animals in suboptimal conditions.

A major driver behind the intensification of meat production is increased demand, as reflected in growing rates of animal product consumption. ${ }^{2}$ According to global trends, "both the average per capita consumption of meat and the total amount of meat consumed are rising, driven by increasing average individual incomes and by population growth" (Godfray et al. 2018). The empirical relationship between increasing income and meat consumption, dubbed Bennett's law (Bennett 1941), means that rates of meat consumption are not equally distributed across all demographics. The dietary habits of wealthy consumers diverge markedly from those of poor producers. Indeed, it is a dark irony that many of the farmers, food processors, and agricultural labourers who are responsible for the world's food supply are often food insecure themselves (Food and Agriculture Organization of the United Nations 2014).

Even though they do not always benefit from the spoils, food and agriculture is a vital source of livelihood for a significant proportion of people in many countries, especially those that are low- or middle-income. As a result, continued access to traditional and staple foods is arguably more important to those who are poor or otherwise marginalized, whereas wealthier classes have ready access to a wider range of options and cannot necessarily fall back on custom alone as a justification for adopting destructive dietary choices (Robinson 2013). This means that, in discussions about reforming food systems - whether in pursuit of better outcomes in terms of public health, environmental sustainability, or food security-social and economic variables should not be left out of the equation.

A food system can be understood as encompassing all of the activities and resources associated with food production and consumption, including growing, harvesting, packing, processing, transforming, transporting, marketing, selling, preparing, eating, and disposing of food and food waste (Food and Agriculture Organization of the United Nations 2018). Due to their complexity, many scholars and activists have advocated for taking a systems approach to tackling the problems and challenges associated with food systems, which "is a way of thinking and doing that considers the food system in its totality, taking into account all the elements, their relationships and related effects" (2: Food and Agriculture Organization of the United Nations 2018). Although many systems approaches look the global food system in its entirety, food systems can also be identified and analyzed at smaller scales, from regional to local.

It is important to bear in mind that at any scale, interventions in any one part of the food system will necessarily have some kind of effect on others, not all of which can be foreseen or accurately predicted. Existing systems approaches have helped bring to light "reinforcing and balancing feedback loops, tensions between the various components and flows of food

\footnotetext{
${ }^{2}$ However, it should be noted that emerging research indicates that COVID-19 has already caused consumers around the world to modify their consumption patterns, including in the form of reduced meat consumption and increased consumption of plant-based alternatives (Bunge and Haddon 2020; Harper 2020). It remains to be seen whether such patterns will hold into the future, as the pandemic eases.
} 
systems, and interactions that are cyclical, multilayered and multi-scale" (3: IPES-Food 2015). For example, the loss of biodiversity and habitat fragmentation attributable to the expansion of intensive livestock production through land use change and deforestation has correspondingly amplified the risk of zoonotic disease emergence and spread by increasing the frequency of encounters between humans, animals used in agriculture, and nonhuman animals to which neither of the aforementioned have traditionally been exposed (World Health Organization and Secretariat of the Convention on Biological Diversity 2015). Accordingly, policies and practices in numerous domains - from agriculture and trade to labour and food safety-all have a part to play both in sustaining current conditions and in moving in a different direction.

\section{Discourse, Dominance, and Demonization}

One of the challenges associated with developing responses to COVID-19 is the fraught nature of the surrounding discourse. Discourse can be defined as "a practice not just of representing the world, but of signifying the world, constituting and constructing the world in meaning" (3: Fairclough 2010). Through discourse, the world is made not just sensical, but also meaningful in particular ways. Thus, the narratives that are assembled through dominant discourses feed directly into the mobilization and validation (or invalidation) of the activities of a wide range of actors.

Value statements are constantly being channelled through language, whether in obvious ways or not. Indeed, even to 'recogniz[e] something as a 'problem' requires a pre-existing set of values as to what is 'normal', 'natural', and thus 'right"' (732: Carolan 2008). In the context of COVID-19, where the science itself is uncertain and rapidly evolving, often poorly reported in the popular media, and subsequently distorted or misunderstood by laypersons, there are several examples that can be drawn on to illustrate the normative assumptions that are embedded in linguistic representations.

Wet markets, in particular, have become something of a lightning rod in discussions about the origins of the COVID-19 pandemic. Within the public discourse, much vitriol has been directed towards wet markets and the cultures in which they are popular, despite the fact that they are far from the only risky practice engaged in the human use of nonhuman animals for purposes of consumption. The point is not that there is anything inherently wrong with using terms like "wet market"; rather, we draw attention to the ways in which terms easily become loaded and, subsequently, deployed differentially in the service of particular narratives.

Despite its claim to neutrality, the discipline of science turns heavily on forms of ordering that rely on particular procedural and interpretive choices. Likewise, the discipline of law, in many ways, depends on classification (31: Adams 2009). Thus, we should not overlook the value conflicts that arise in mixing the purportedly objective realms of science and the law with cultural practices. For example, the classification of some animals as "wild" (as contrasted with "domestic") does not lie in some a priori demarcation, but is instead socially determined (Deckha and Pritchard 2016).

Relatedly, as animal studies scholars have long pointed out, the line between the animals that are seen as comestible commodities and those that are seen as cherished companions (and thereby afforded greater protections at law) is a relative one, rather than representing some kind of absolute hierarchy (Joy 2010; Overcash 2012). Yet, the instinctive revulsion that many Westerners feel at the thought of eating species like dogs regularly translates into the harmful perpetuation of racial stereotypes about the deviance of the Asian cultures in which dog eating 
is not as taboo as it is in Western cultures (Wu 2002). We caution against the unreflective reliance on sensationalistic, clichéd tropes that do not adequately consider the cultural and historical contingence of gastronomical norms.

More broadly, although there have been many major changes in the food system in recent years, there are also some practices or traditions that have remained stable, explained partly by the fact that they are culturally entrenched. Acquiring food is not a purely utilitarian or commercial transaction, and in many cultures, the rich tapestry of food markets acts as a central site of social exchange. As a result, numerous factors can be pointed to as an explanation for why the ubiquity of supermarkets and their corresponding dominance as the primary source of food for the majority of consumers in high-income countries is not necessarily paralleled in other parts of the world ( $\mathrm{Si}$ et al. 2019).

Despite the sinister connotations that have been ascribed to them as of late, wet markets are essentially just places in which fresh produce, aquatic and land-based animals consumed as meat (which might be slaughtered or live at the time of purchase), and other perishable goods are sold. ${ }^{3}$ Under such a definition, even your friendly neighbourhood farmer's market constitutes a wet market, though this label is rarely used in the Western context. Indeed, a supermarket with an in-house butcher, or a seafood counter offering fresh fish alongside live crustaceans blurs these lines even more.

Nonetheless, the term "wet market" has become closely linked to the exotification of the dietary habits of certain countries, and, in turn, adverse associations between those habits and equally exotified diseases. Further complicating matters, wet markets are often conflated with wildlife markets, which specifically sell a range of animals, whether for human consumption or for other purposes. Wildlife may be found at wet markets, but not all wet markets are wildlife markets. Neither type of market is unique to China, or even to Asia, as both can be found around the world, even if not referred to by that name (Alberts 2020).

A similar phenomenon can be seen with the term "bushmeat", frequently associated with Sub-Saharan Africa. At its root, bushmeat simply refers to wild meat. As such, the same term could just as readily be applied to dishes commanding high prices in the poshest restaurants of North America and Western Europe. Yet, negative connotations with zoonotic diseases such as the Ebola virus have come to subsume far broader practices of hunting, trading and consumption as an accessible source of protein and a source of income for many communities (Davies and Brown 2007). This serves to undermine efforts to identify particular public health risks and the specific behaviours that fuel them, and which could be targeted for reform without stigmatizing entire communities or lifestyles.

Drawing on the example of Singapore, Mele et al. (2015) have observed that "[s]ocial, political and economic contexts shape how the social functions of urban markets are experienced and interpreted" (104). Hence, wet markets are "significant and unique social spaces that increasingly matter within the context of modernisation and advanced urbanism" (105: Mele et al. 2015). Just as food is a requirement to sustain life, humans are social creatures who rely on social exchanges and interactions to inform many aspects of their health and well-being. Against the backdrop of "a shifting urban landscape, a concomitant disappearance of unregulated community space, and the pervasiveness of normative consumerism" (105: Mele et al.

\footnotetext{
3 One explanation is that the term "wet" is in reference to the wetness of the floor in such markets "as a result of the frequent spraying of produce and the cleaning of meat and fish stalls" (138, note 1: Goldman et al. 1999). Another explanation is that the term "wet" is used as a contrast to "dry" markets that trade in non-perishable, durable goods like grains or household products (Westcott and Wang 2020).
} 
2015), traditional practices and settings, like markets, provide "a social space of stability" and can be seen as "stand[ing] as a corrective to the excesses of modernisation" (116: Mele et al. 2015). Wet markets therefore reveal an uneasy tension between modernization as both origin of and solution to cultural practices that are deemed to be problematic.

Modernization generally refers to the cultural and socio-economic process whereby traditional societies become urban and industrial (Inglehart and Baker 2000). Whether implicitly or explicitly, discussions of the concept of modernization frequently carry normative judgments about the desirability of these kinds of transformations. Goldman et al. define food retail modernization as involving "the replacement of traditional retail formats by modern ones" (127: 1999). This tautological definition is clarified by an elaboration of some features of traditional food retail systems, including that they are typically small, family operated, employ marginal labor, and that stores are "cluttered, dirty, and unorganized" (127: Goldman et al. 1999). Despite this less than positive assessment, they also note that traditional retail outlets, like wet markets, can offer the advantages of lower prices, fresher products, and an environment conducive to social interaction (Goldman et al. 1999). Thus, as a practical matter, traditional retail outlets can be an important source of fresh, affordable, and culturally appropriate ${ }^{4}$ food for people in many countries. Demonizing wet markets - by using the term primarily in a way that both ethnicizes it and emphasizes its perceived role as a source of disease-discredits the qualities that explain, at least in part, their enduring popularity, and finding alternative ways to fill the gaps that would be left by doing away with them is crucial to developing ethical and effective solutions to the concerns that they raise.

Moving from wet markets as a perceived source of contagion to broader perceptions of the origins of disease, problems relating to discursive choices have also been explicitly recognized but not yet overcome when it comes to novel diseases. For instance, the World Health Organization's (WHO) Best Practices for the Naming of New Human Infectious Diseases explicitly rejects numerous elements, including geographic locations, species or classes of animals, and cultural, population, industry or occupational references (World Health Organization 2015). Both historically (e.g. Spanish flu, monkeypox) and more recently (e.g. Middle East Respiratory Syndrome, swine flu), diseases have been named without taking such precautions against potentially fostering such connections and attendant discrimination. By contrast, for COVID-19, and the underlying virus SARS-CoV-2, this guidance has been followed. However, the fact the novel coronavirus was not thus christened until February 11, 2020, nearly 2 weeks after the WHO had declared it to be a Public Health Emergency of International Concern, may have been a missed opportunity to better control the public discourse before figures like Donald Trump explicitly adopted inflammatory terminology.

The intimate connections between power, position, and language mean that not all of us are equally situated to define what constitutes the "truth". In this way, "choices about whom to trust, what to believe, and why something is true are not benign academic issues" (130: Janack 1997). The racialization of certain practices and the use of inflammatory us-versus-

\footnotetext{
${ }^{4}$ Demands for fresh, affordable, and culturally appropriate food are frequently presented as part of a push towards embracing the broader concept of food sovereignty. Though a full discussion of food sovereignty is beyond the scope of this article, food sovereignty is defined as "the right of peoples to healthy and culturally appropriate food produced through ecologically sound and sustainable methods, and their right to define their own food and agriculture systems" (1: Declaration of Nyéléni 2007). Beyond seeking to conceptualize food as more than just a commodity, the food sovereignty paradigm recognizes that there are myriad anthropological and historical reasons why what constitutes an optimal diet for one person or group may not be ideal for another.
} 
them rhetoric belies the reality that disease outbreaks caused by viral pathogens are the result of not any one factor, but the culmination of multiple variables. Consequently, ethically appropriate responses to COVID-19 must acknowledge that wrongness and rightness in this context is not black and white, and is in many ways a matter of perspective and privilege.

\section{Diversity and Difference}

Unsurprisingly, the linkage of the COVID-19 pandemic with a wet market has prompted cries for such markets to be permanently banned (Greenfield 2020; The Lion Coalition 2020). Given the extent of the implications, wholesale prohibition has not been the position endorsed by organizations like the WHO. However, the WHO did recently release a number of recommendations as to how to reduce the risk of transmission of emerging pathogens in live animal markets or animal product markets. The recommendations promote, inter alia, good hygiene practices among all those who visit or work at such markets, and vigilance with respect to the health of animals slaughtered for consumption (World Health Organization 2020).

Some have criticized calls for stricter safety and hygiene standards as not going far enough, but as a group of researchers at the University of Oxford have pointed out, the impact of bans "cannot be assumed to be positive. They could also do more harm than good for biodiversity" (Challender et al. 2020). As has been observed in other contexts (e.g. illicit substances used for recreational purposes), prohibiting an activity does not miraculously make it go away. Instead, it pushes it further outside the bounds of formal monitoring and enforcement mechanisms. Blanket bans are also impractical, especially over the long term. Thus, rather than using COVID-19 "opportunistically to prescribe global wildlife trade policy", Challender et al. (2020) argue that "[a] more appropriate response would be to improve wildlife trade regulation with a direct focus on human health." The takeaway here is that poor regulation of risky practices and the continuance of illegal trade in wildlife are major concerns that should be better addressed irrespective of where they take place.

In developing robust policies that have the best chances of being effective and appropriate, context specificity is important. In accounting for contextual factors, scale is worth bearing in mind. With slightly less than one-fifth of the world's population, the behaviours of even a small percentage of China's populace are likely to directly affect more people than elsewhere, even where such behaviours are not unique to the country. At the same time, there are noteworthy features of the current Chinese model that have caused Chinese wet markets to be described as "unique place[s] for transmission of zoonotic disease to humans" (403: Woo et al. 2006).

Some of these factors are distinctly cultural. Woo et al. (2006) note that these include, for example, "the predilection of the southern Chinese to special delicacies", and "high-risk behaviors of customers, such as blowing the cloacae of chickens commonly practised to examine their healthiness" (403). Others are economic - for example, rapid growth has lifted hundreds of millions of citizens into the middle class. Not only have they adhered to Bennett's law in their increased consumption of meat, with the attendant pressures on production, but higher incomes have also fuelled demands for wildlife (Zhang et al. 2008). Even in the case of animals that have traditionally been consumed in the country, higher incomes have allowed the scale of consumption to increase. This demand affects the means and sources of production in turn. Wildlife for consumption can come from domestic or foreign sources, creating further pathways for the emergence of zoonotic disease. 
China is one of the leading countries in both the legal and illegal trade and consumption of wildlife (Smiley Evans et al. 2020). Take pangolins, which are endangered scaled anteaters found in parts of Asia and Africa that have been widely linked to COVID-19. While their ultimate role, if any, remains unproven, the pandemic has drawn attention to the fact that pangolins are one of most trafficked mammals in the world, if not the most (United Nations Office on Drugs and Crime 2020). Pangolins, which are consumed both as food and used in Traditional Chinese Medicine (TCM), are imported from other countries, creating new opportunities for the intermingling of diverse animals and the even more diverse diseases they may harbour. Various other animals are sourced and consumed in a similar manner.

To its credit, China has undertaken explicit legal measures to shift consumption of wildlife away from wild-hunted towards captive-bred animals (Wang et al. 2019), representing a move in the right direction, albeit being perhaps an imperfect solution. China has also promoted commercial farming of wildlife as a source of income for poor farmers (Standaert 2020). While farmed game is popular in many countries, not just China, and while farmed supplies may serve to protect wild populations, farming can also create new opportunities for the spread of disease, particularly under crowded, unsanitary conditions. Such risks also apply to the farming of less exoticized species. For example, since it was first identified in 2013, multiple waves of H7N9 influenza, associated with live poultry markets, have caused deaths in China ( $\mathrm{Su}$ et al. 2017). It is entirely feasible that a similar outbreak could occur elsewhere - pathogens track to certain conditions, not to countries or cultures. History bears out the fact that diseases do not discriminate; for instance, the 2009 H1N1 pandemic appears to have originated in pig farms in Mexico (Gibbs et al. 2009; Mena et al. 2016).

In the past, China has shown a willingness to adopt stringent measures in the response to immediate threats of zoonotic disease, at least in the short term. For instance, facing a potential resurgence of SARS in Guangdong in January of 2004, officials shut down wildlife markets and culled over 10,000 animals, including civet cats, that had previously been identified as potential carriers (Watts 2004). More recently, in response to COVID-19, China banned the consumption of wild animals (Xie 2020). It is unclear whether this ban will remain permanently in place to prevent future outbreaks of disease, or whether the restrictions will be loosened when the current pandemic subsides. However, long-term measures to prevent future threats must account for the serious economic impact on those who depend on the multi-billion dollar trade in wildlife as a source of livelihood, and as a source of food. Furthermore, it is both unfair and unrealistic to place the entire burden on China. Many of these issues arise all over the world and so should be examined and remedied, as necessary, wherever they occur.

To shine a spotlight on China's wet and/or wildlife markets is not to ignore the problematic aspects of the models of industrial animal agriculture that are common in wealthy Western nations. As noted earlier, the overuse of antibiotics in the agricultural industry in many countries has contributed to the attendant risk of drug resistance, with serious ramifications for public health (World Health Organization 2017). Industrial farming also generates a considerable volume of animal waste, often subject to less stringent regulation than its human equivalent, which can contaminate air and water supplies (Graham et al. 2008; Thorne 2007).

Meanwhile, in both Canada and the United States, meat-packing plants have been identified as major sites of COVID-19 transmission (Dryden and Rieger 2020; Lakhani 2020), which has exposed the vulnerability of both the nonhuman animals and the people who are enclosed in such environments. Outbreaks of COVID-19 at food processing facilities have also 
accentuated the dangers of increasing corporate consolidation and control in the food system, against which scholars have previously warned (Clapp 2018). While relying on fewer farms and processing facilities may increase "efficiency" in the eyes of the large, transnational corporations that are holding increasingly greater power over the food supply, the trade-offs of this model in terms of environmental, human, and ethical costs are immense (Shanker 2017).

These are all serious issues that deserve careful attention. In each of these cases, the solution is not as simple as doing away with a production or consumption practice altogether; nor does a quick fix lie in technological workarounds (Lee 2019). Though there are undoubtedly health, environmental, and ethical benefits to be reaped by drastically (or even modestly) reducing rates of animal product production or consumption, the problem is not necessarily animal product production or consumption per se (Lee 2019). Rather, the problem lies in the larger paradigms within which animal product production and consumption are currently situated.

Critiques of a model that prioritizes short-term profits and privileges narrow political interests are by no means new, but the very real perils associated with a business-as-usual trajectory are perhaps more starkly apparent than ever before. We are currently being presented with a unique opportunity to interrupt dangerous patterns that should not be missed, as climate change effects may further exacerbate the risk of zoonotic diseases (Mills et al. 2010). The environmental destruction and social impacts associated with anthropogenic climate change is already one of the most defining challenges of our time. Clean air, fresh water, and fertile soil are not only important to preserve as the basic building blocks on which growing and producing food depends, but agriculture is also a key driver of global environmental change (Poore and Nemecek 2018). Putting food systems on more sustainable footing is therefore a necessary precondition to producing improved ethical, environmental, and public health outcomes for both our own and for future generations.

The hegemony of the status quo makes change difficult, but not impossible. If reforms are to be meaningful, they must represent more than just a temporary fix that only speaks to one dimension of the problem. Ultimately, this means that we must challenge some of the most fundamental tenets on which our political, economic, and social structures rest, including the premises upon which our relationship with nature is founded. The conceit of human control over nature is increasingly tenuous, and the more we interfere with delicate ecological balances for our own benefit, the more negative consequences we are likely to trigger, with increasingly far-reaching implications. Given the steep ecological debts that we have already incurred, these are gambles that we cannot afford to take.

To return to an earlier point, it is not imperialistic to critique cultural practices and call for reforms in the light of changed circumstances. The amplified risks of certain production and consumption practices in a modern world characterized by population growth, concomitant increases in levels of consumption, and globalization means that behaviours that have been embraced or even simply tolerated in the past are no longer justified, particularly when their ramifications are severe, rapid, and near universal. Nevertheless, in devising and structuring reform, we should be wary about demanding that other cultures adhere to the values and standards of our own, particularly when doing so distracts from the need to remedy our own failings. Long-standing and deeply engrained traditions cannot be expected to change overnight, and our national and international policies must retain not just room, but genuine tolerance for diversity and difference, as well as a shared interest in preventing a repeat of the current public health catastrophe engulfing the globe. 


\section{Conclusion}

There is no simple or singular answer that will adequately address the multifaceted global challenges that the COVID-19 pandemic has made impossible to ignore. It is also important to remember that responsibility for reform is not necessarily connected to one's degree of culpability. As Iris Marion Young put it, "where there are structural injustices, finding that some people are guilty of perpetrating specific wrongful actions does not absolve others whose actions contribute to the outcomes from bearing responsibility in a different way" (106: Young 2006). With respect to the way that we treat and (ab)use nonhuman animals, whether at individual, institutional, or international levels, we are all implicated in both the problems and the solutions. A more constructive moral dialogue should therefore open the full range of animal practices up to scrutiny, regardless of where they originate (Kim 2007).

The public health, environmental, and ethical consequences of food production and consumption choices are closely tied to any number of insidious problems that are perpetuated by a wide range of actors. Thus, presenting the wholesale elimination of wet markets (either in their broadest sense, or those reflecting particular cultural traditions) or other extreme options such as advocating for universal vegetarianism or veganism greatly oversimplifies the problems, the solutions, and who should be considered to be the guilty parties. Focusing on assigning blame and pointing fingers is unfair to the extent that it frequently reflects a cultural double standard, and is unproductive insofar as it rarely gets to the roots of the issues.

Furthermore, leaving very real intergenerational and intragenerational equity issues out of dialogues about interspecies justice does a disservice to any holistic efforts to prompt the kinds of transformative changes we will need to see in any version of a more equitable and sustainable future. Improving interspecies relations will be of little benefit to anybody if life as we know it ends. In the face of ecological catastrophe, all social, economic, and ethical aspirations are, by default, subsidiary to the bigger goal of preserving ecological integrity, both now and into the future. To this end, many scholars and activists, including the International Panel of Experts on Sustainable Food Systems (IPES-Food), have argued that measures taken to curb the COVID-19 crisis must be "the starting point for a food system transformation that builds resilience at all levels" (1: IPES-Food 2020). For this to be the case, the attention, energy, and resources devoted to such an endeavour must be increased accordingly, and we must look beyond piecemeal and reactive solutions.

When it comes to highly complex issues, both the substance and the form of the conversation matters. Undoubtedly, we are being confronted with urgent issues that demand equally urgent solutions, and in the wake of COVID-19, there has been no shortage of hot takes from across the political spectrum. However, the proliferation of uninformed, knee-jerk, reactionary responses can be more harmful than it is helpful, especially if they rely on incendiary or otherwise problematic rhetoric. When differently situated parties talk past one another instead of to one another, the result is an increasingly acrimonious debate in which the focus on commonly shared goals and aspirations easily becomes lost.

Acknowledging our fundamental interconnectedness is one way of overcoming such counterproductive polarization. The food system is a potent manifestation of this interconnectedness, insofar as we all depend on food for sustenance, and all of our food comes from the same Earth. As such, we are all better served by food systems that inculcate mutual care, respect for each other, for other species, and for all of nature, as well as an acknowledgement of our mutual dependencies. We hope that this article can contribute to more measured 
reflections that encourage everyone to seek greater understanding, greater empathy, and a greater willingness to engage in the collective work of trying to build a better world for humans and nonhuman animals alike.

\section{Compliance with Ethical Standards}

Conflict of Interest On behalf of all authors, the corresponding author states that there is no conflict of interest.

\section{References}

Adams, Wendy A. 2009. Human subjects and animal objects: Animals as “other" in law. Journal of Animal Law \& Ethics 3 (1): 29-51.

Alberts, Elizabeth Claire. 2020. What's in a name? 'Wet markets' may hide true culprits for COVID-19. Mongabay. https://news.mongabay.com/2020/04/whats-in-a-name-wet-markets-may-hide-true-culprits-forcovid-19/. Accessed 12 July 2020.

Bennett, M.K. 1941. Wheat in national diets. Wheat Studies 18 (2): 37-76.

Bunge, Jacob and Heather Haddon. 2020. Coronavirus meat shortages have plant-based food makers' mouths watering. The Wall Street Journal. https:/www.wsj.com/articles/coronavirus-meat-shortages-have-plantbased-food-makers-mouths-watering-11589371206. Accessed 18 May 2020.

Burke, Jason, Emmanuel Akinwotu and Lily Kuo. 2020. China fails to stop racism against Africans over Covid19. The Guardian. https://www.theguardian.com/world/2020/apr/27/china-fails-to-stop-racism-againstafricans-over-covid-19. Accessed 17 May 2020.

Carolan, Michael S. 2008. The bright- and blind-spots of science: Why objective knowledge is not enough to resolve environmental controversies. Critical Sociology 34 (5): 725-740.

Challender, Dan et al. 2020. Coronavirus: Why a blanket ban on wildlife trade would not be the right response. The Conversation. https://theconversation.com/coronavirus-why-a-blanket-ban-on-wildlife-trade-would-notbe-the-right-response-135746. Accessed 15 May 2020.

Clapp, Jennifer. 2018. Mega-mergers on the menu: Corporate concentration and the politics of sustainability in the global food system. Global Environmental Politics 18 (2): 12-33.

Davies, Glyn, and David Brown, eds. 2007. Bushmeat and livelihoods: Wildlife management and poverty reduction. Malden: Blackwell Publishing.

Deckha, Maneesha, and Erin Pritchard. 2016. Recasting our 'wild' neighbours: Contesting legal otherness in urban human-animal conflicts. UBC Law Review 49 (1): 161-202.

Declaration of Nyéléni. 2007. https://nyeleni.org/IMG/pdf/DeclNyeleni-en.pdf. Accessed 12 July 2020.

Dryden, Joel and Sarah Rieger. 2020. Inside the slaughterhouse. CBC News. https://newsinteractives.cbc. ca/longform/cargill-covid19-outbreak. Accessed 15 May 2020.

Fairclough, Norman. 2010. Critical discourse analysis: The critical study of language. 2nd ed. New York: Routledge.

Food and Agriculture Organization of the United Nations. 2014. The state of food and agriculture $2014-$ Innovation in family farming. Rome: FAO.

Food and Agriculture Organization of the United Nations. 2018. Sustainable food systems: Concept and framework. http://www.fao.org/3/ca2079en/CA2079EN.pdf. Accessed 15 May 2020.

Gibbs, Adrian J., John S. Armstrong, and Jean C. Downie. 2009. From where did the 2009 "swine-origin" influenza a virus (H1N1) emerge? Virology Journal. 6 (1): 207.

Godfray, H., J. Charles, et al. 2018. Meat consumption, health, and the environment. Science. https://doi. org/10.1126/science.aam5324.

Goldman, Arieh, Robert Krider, and S. Ramaswami. 1999. The persistent competitive advantage of traditional food retailers in Asia: Wet markets' continued dominance in Hong Kong. Journal of Macromarketing 19 (2): 126-139.

Graham, Jay P., et al. 2008. The animal-human Interface and infectious disease in industrial food animal production: Rethinking biosecurity and biocontainment. Public Health Reports 123 (3): 282-299.

Greenfield, Patrick. 2020. Ban wildlife markets to avert pandemics, says UN biodiversity chief. https://www. theguardian.com/world/2020/apr/06/ban-live-animal-markets-pandemics-un-biodiversity-chief-age-ofextinction. Accessed 15 May 2020.

Harper, Justin. 2020. 'Fake' meat on the menu as China reopens restaurants. BBC News. https://www.bbc. com/news/business-52391517. Accessed 18 May 2020. 
Inglehart, Ronald, and Wayne E. Baker. 2000. Modernization, cultural change, and the persistence of traditional values. American Sociological Review 65 (1): 19-51.

IPES-Food. 2015. The new science of sustainable food systems: Overcoming barriers to food systems reform. Brussels: International Panel of Experts on Sustainable Food Systems.

IPES-Food. 2020. COVID-19 and the crisis in food systems: Symptoms, causes, and potential solutions. http://www.ipes-food.org/_img/upload/files/COVID-19_CommuniqueEN\%283\%29.pdf. Accessed 17 May 2020.

Janack, Marianne. 1997. Standpoint epistemology without the "standpoint"?: An examination of epistemic privilege and epistemic authority. Hypatia 12 (2): 125-139.

Janes, Craig R., et al. 2012. Emerging infectious diseases: The role of social sciences. The Lancet 380 (9857): 1884-1886.

Joy, Melanie. 2010. Why we love dogs, eat pigs, and Wear cows: An introduction to Carnism. San Franciso: Conari Press.

Kim, Claire Jean. 2007. Multiculturalism Goes Imperial. Du Bois Review 4 (1): 233-249.

Lakhani, Nina. 2020. US coronavirus hotspots linked to meat processing plants. The Guardian. https://www. theguardian.com/world/2020/may/15/us-coronavirus-meat-packing-plants-food. Accessed 15 May 2020.

Lee, Angela. 2019. The Milkmaid's tale: Veganism, feminism, and dystopian food futures. Windsor Review of Legal and Social Issues 40: 27-66.

The Lion Coalition. 2020. Open letter to World Health Organization. The Lion Coalition. https://ioncoalition. org/2020/04/04/open-letter-to-world-health-organisation/. Accessed 15 May 2020.

Mele, Christopher, Megan Ng, and May Bo Chim. 2015. Urban markets as a 'corrective' to advanced urbanism: The social space of wet markets in contemporary Singapore. Urban Studies 52 (1): 103-120.

Mena, Ignacio, et al. 2016. Origins of the 2009 H1N1 influenza pandemic in swine in Mexico. eLife. 5: e16777.

Mills, James N., Kenneth L. Gage, and Ali S. Khan. 2010. Potential influence of climate change on vector-borne and zoonotic diseases: A review and proposed research plan. Environmental Health Perspectives. https://oi. org/10.1289/ehp.0901389.

Nakamura, David. 2020. With 'kung flu,' Trump sparks backlash over racist language - and a rallying cry for supporters. The Washington Post. https://www.washingtonpost.com/politics/with-kung-flu-trump-sparksbacklash-over-racist-language \%2D\%2Dand-a-rallying-cry-for-supporters/2020/06/24/485d151e-b620-11eaaca5-ebb63d27e1ff_story.html. Accessed 12 July 2020.

Overcash, Elizabeth Ann. 2012. Unwarranted discrepancies in the advancement of animal law: The growing disparity in protection between companion animals and agricultural animals. North Carolina Law Review 90: $837-883$.

Poore, J., and T. Nemecek. 2018. Reducing food's environmental impacts through producers and consumers. Science 360: 987-992.

Robinson, Margaret. 2013. Veganism and Mi'kmaq Legends. The Canadian Journal of Native Studies 33 (1): 189-196.

Shanker, Deena. 2017. There Aren't enough slaughterhouses to support the farm-to-table economy. Bloomberg. https:/www.bloomberg.com/news/articles/2017-05-23/there-aren-t-enough-slaughterhouses-to-support-thefarm-to-table-economy. Accessed 12 July 2020.

Si, Zhenzhong, Steffanie Scott, and Cameron McCordic. 2019. Wet markets, supermarkets and alternative food sources: Consumers' food access in Nanjing, China. Canadian Journal of Development Studies 40 (1): 78 96.

Smiley Evans, Tierra, et al. 2020. Synergistic China-US ecological research is essential for global emerging infectious disease preparedness. EcoHealth. 17 (1): 160-173.

Standaert, Michael. 2020. Coronavirus closures reveal vast scale of China's secretive wildlife farm industry. The Guardian. https://www.theguardian.com/environment/2020/feb/25/coronavirus-closures-reveal-vast-scaleof-chinas-secretive-wildlife-farm-industry. Accessed 16 May 2020.

Sternlicht, Alexandra. 2020. With new COVID-19 outbreak linked to gay man, homophobia on rise in South Korea. Forbes. https://www.forbes.com/sites/alexandrasternlicht/2020/05/12/with-new-covid-19outbreak-linked-to-gay-man-homophobia-on-rise-in-south-korea/\#7cc1 fa1a4909. Accessed 17 May 2020.

$\mathrm{Su}$, S. et al. 2017. Epidemiology, evolution, and pathogenesis of H7N9 influenza viruses in five epidemic waves since 2013 in China. Trends in Microbiology. 25 (9): 713-728.

Thorne, Peter S. 2007. Environmental health impacts of concentrated animal feeding operations: Anticipating hazards_-Searching for solutions. Environmental Health Perspectives 115 (2): 296-297.

United Nations Office on Drugs and Crime. 2020. Wildlife Crime: Pangolin scales. https://www.unodc. org/documents/wwcr/2020/Wildlife_crime_Pangolin_UNODC.pdf. Accessed 16 May 2020.

Vincent, Danny. 2020. Africans in China: We face coronavirus discrimination. BBC News. https://www.bbc. com/news/world-africa-52309414. Accessed 17 May 2020. 
Wang, Wenxia, et al. 2019. Captive breeding of wildlife resources-China's revised supply-side approach to conservation. Wildlife Society Bulletin. 43 (3): 425-435.

Watts, Jonathan. 2004. China culls wild animals to prevent new SARS threat. The Lancet. 363 (9403): 134.

Westcott, Ben and Serenetie Wang. 2020. China's wet markets are not what some people think they are. CNN. https://www.cnn.com/2020/04/14/asia/china-wet-market-coronavirus-intl-hnk/index.html. Accessed 17 May 2020.

Woo, Patrick C.Y., Susanna K.P. Lau, and Kwok-Yung Yuen. 2006. Infectious diseases emerging from Chinese wet-markets: Zoonotic origins of severe respiratory viral infections. Current Opinion in Infectious Diseases 19 (5): 401-407.

World Health Organization. 2015. World Health Organization best practices for the naming of new human infectious diseases. https://apps.who.int/iris/bitstream/handle/10665/163636/WHO_HSE_FOS_15.1_eng. pdf. Accessed 16 May 2020.

World Health Organization. 2017. WHO guidelines on use of medically important antimicrobials in foodproducing animals. Geneva: World Health Organization.

World Health Organization. 2020. WHO recommendations to reduce risk of transmission of emerging pathogens from animals to humans in live animal markets or animal product markets (26 March 2020). https://www. who.int/health-topics/coronavirus/who-recommendations-to-reduce-risk-of-transmission-of-emergingpathogens-from-animals-to-humans-in-live-animal-markets. Accessed 12 May 2020.

World Health Organization and Secretariat of the Convention on Biological Diversity. 2015. Connecting global priorities: Biodiversity and human health - A state of knowledge review. Geneva: World Health Organization.

Wu, Frank H. 2002. The best "chink" food: Dog eating and the dilemma of diversity. Gastronomica 2 (2): 38-45.

Xie, Echo. 2020. China bans trade, eating of wild animals in battle against coronavirus. South China Morning Post. https://www.scmp.com/news/china/article/3052151/china-bans-trade-eating-wild-animals-battleagainst-coronavirus. Accessed 16 May 2020.

Young, Iris Marion. 2006. Responsibility for justice. New York: Oxford University Press.

Zhang, Li, Ning Hua, and Shan Sun. 2008. Wildlife trade, consumption and conservation awareness in Southwest China. Biodiversity and Conservation 17 (6): 1493-1516.

Zimmer, Ben. 2020. Why trump intentionally misnames the coronavirus. The Atlantic. https://www.theatlantic. com/culture/archive/2020/03/why-trump-intentionally-misnames-coronavirus/607900. Accessed 19 June 2020.

Publisher's Note Springer Nature remains neutral with regard to jurisdictional claims in published maps and institutional affiliations. 